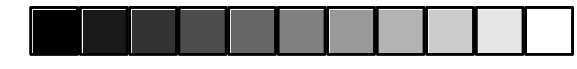

\title{
CRISIS FINANCIERAS INTERNACIONALES, PRESTAMISTA DE ULTIMA INSTANCIA Y NUEVA ARQUITECTURA FINANCIERA INTERNACIONAL*
}

\author{
EsTEBAN J ADRESIC ${ }^{* *}$ \\ Klaus Schmidt-HebBeL ${ }^{* * *}$ \\ RODRIGO VALDÉS ${ }^{* * * *}$
}

\begin{abstract}
The international financial system (IFS) has undergone a series of financial crises over the past decade. This paper analyzes the shortcomings of said system (that have contributed to the crises) and, with them in mind, reviews and evaluates the IFS reform proposals for a "New International Financial Architecture." These proposals are intended to resolve IFS imperfections on three fronts: better crisis prevention, better crisis resolution, and better governance at the IMF, the international quasi lender of last resort. Although a number of the proposals are academic, they have been useful for the reforms that the IMF has either implemented or supported actively. These include adopting standards and codes in 12 key areas for domestic and international financial stability, such as improved country monitoring, stricter conditions for financial aid granted to countries in crisis, better IMF governance, and new collective action clauses in issuing sovereign bonds. In contrast, the IMF has found no significant support for its proposals of creating a contingent credit line and adopting mechanisms to restructure sovereign debts. But no IFS reform is a good substitute for good fundamentals at the country level, that reflect strong macroeconomic and structural policies, the best way to reduce the probability of occurrence of liquidity or solvency crises.
\end{abstract}

* Este trabajo representa sólo la opinión de sus autores y no compromete al Banco Central de Chile ni a su Consejo. Agradecemos la excelente asistencia y los comentarios * provistos por Roberto Duncan.

**_Banco Central de Chile, email: ejadresi@bcentral.cl.

***_Banco Central de Chile, email: kschmidt@bcentral.cl

**** Banco Central de Chile, email: rvaldes@bcentral.cl.

Keywords: Lender of Last Resort, Central Banks, Commercial Banks, Financial Crises, International Monetary Fund.

JEL Classification: F33, F34, F36, G15 


\section{RESUMEN}

El sistema financiero internacional (SFI) ha vivido una secuencia de crisis financieras durante la última década. Este trabajo analiza las imperfecciones del sistema financiero internacional (que han contribuido a las crisis) y, a la luz de ellas, revisa y evalúa las propuestas de reforma del SFI para una "Nueva Arquitectura Financiera Internacional". Las propuestas apuntan a superar las imperfecciones del SFI en tres dimensiones: mejor prevención de crisis, mejor resolución de crisis y mejor gobernabilidad del FMI, el cuasi-prestamista de última instancia internacional. Aunque muchas de las propuestas son académicas, ellas han servido para las reformas que el FMI ha implementado o apoyado activamente. Entre éstas destacan la adopción de estándares y códigos en 12 áreas claves para la estabilidad financiera nacional e internacional, el mejor monitoreo de países, la condicionalidad más estricta en la asistencia financiera otorgada a países en crisis, la mejor gobernabilidad del FMI y la incorporación de cláusulas de acción colectiva en las emisiones de bonos soberanos. En contraste, no han encontrado mayor apoyo las propuestas del FMI para una línea de crédito contingente y la adopción de mecanismos de reestructuración de deuda soberana. Pero ninguna reforma del SFI es un sustituto de fundamentales sólidos a nivel de países, que reflejan políticas macroeconómicas y estructurales como la mejor forma para asegurar una baja probabilidad de ocurrencia de crisis de liquidez o solvencia.

\section{INTRODUCCIÓN}

El sistema financiero internacional ha vivido una secuencia de crisis financieras iniciadas en una economía emergente de importancia (el epicentro de la crisis) y con secuelas relevantes -contagio- para otras economías emergentes (la periferia de la crisis). Entre dichas crisis están las que se inician en los epicentros de México (1994), Asia (1997) y Rusia (1998). Las crisis posteriores en economías emergentes grandes -incluyendo Brasil (1998), Turquía (1999) y Argentina (2001-02) - no se han propagado a otras economías, pero han contribuido desde 1998 a la dirección perversa de los flujos netos de capitales (desde los países en desarrollo hacia los desarrollados) y a su elevada volatilidad.

Las crisis financieras son crisis de la cuenta de capitales derivadas de una aguda caída en la entrada neta de capitales privados, dificultando severamente la posibilidad de cumplir con las obligaciones de pagos externos. Típicamente es difícil distinguir entre crisis de liquidez y solvencia. La intensidad de una crisis de liquidez internacional aumenta con la rigidez del sistema cambiario y la debilidad del sistema bancario doméstico, pudiendo combinarse con una crisis melliza, vale decir, con el colapso simultáneo de un sistema de cambio inflexible y de la banca doméstica. También se intensifica con la debilidad de las cuentas fiscales y del sistema político, que inhibe la adopción de políticas macroeconómicas y estructu- 
rales de emergencia y de corrección sistémica. La simultaneidad de las debilidades anteriores eleva la probabilidad que una crisis de cuenta de capitales -incrementada por crisis de balanza de pagos, bancaria y política- termine en el repudio unilateral de la deuda externa. El caso de Argentina desde fines de 2001 representa precisamente este extremo. Constituye una quíntuple crisis financiera externa, cambiaria, fiscal, bancaria y política, que culminó en el repudio unilateral de su deuda externa.

La estructura del SFI está caracterizada por un mercado dominante de flujos privados de capitales entre países soberanos y un mercado secundario de préstamos de instituciones financieras internacionales (IFIs) a gobiernos de países en desarrollo. Los préstamos de las IFIs incluyen tanto a los préstamos para proyectos de desarrollo otorgados en condiciones normales como la provisión de liquidez en condiciones de crisis financieras externas, ambos sujetos a condiciones específicas que imponen las IFIs a los deudores. En el rol que juegan las IFIs como proveedores de liquidez, el Fondo Monetario Internacional (FMI) juega un papel central al determinar la oportunidad, condicionalidad y coordinación de los préstamos de rescate financiero otorgadas por las IFIs. En este sentido, el FMI juega un papel de cuasi-prestamista de última instancia (cuasi-PUI) a nivel internacional. Su mayor limitación consiste en la escasez de recursos con que cuenta el FMI para la asistencia financiera de países en crisis, en comparación con los mayores recursos relativos con los que cuentan los bancos centrales nacionales. Otra diferencia entre el FMI y los PUIs nacionales consiste en el significativo papel del FMI como institución otorgadora del sello de aprobación a los programas de ajuste adoptados por países en crisis, que constituye una condición necesaria para acceder a fondos de otras IFIs y del sector privado.

La literatura especializada, los analistas internacionales y las propias IFIs atribuyen el creciente número de crisis financieras a distintas imperfecciones estructurales del sistema financiero internacional (SFI), observadas al menos hasta el comienzo de la crisis asiática. Algunas de estas imperfecciones replican, a escala global, las imperfecciones propias de un sistema financiero nacional. Sin embargo, el SFI internacional exhibe imperfecciones adicionales que se derivan del hecho de que los contratos financieros internacionales se realizan entre estados soberanos o residentes en estados soberanos distintos, separados por distintos sistemas legales, políticas económicas y condiciones políticas. La soberanía nacional en la legislación, el sistema judicial y las decisiones políticas nacionales aún no es reemplazada por las correspondientes instituciones internacionales en los mercados financieros internacionales. Más aún, el otorgamiento de créditos de emergencia en situación de crisis por las IFIs, lideradas por el FMI, pueden contribuir al riesgo moral reflejado en excesivos flujos de capitales desde acreedores privados hacia deudores soberanos.

El objetivo de este trabajo es analizar las imperfecciones del SFI y, a la luz de ellas, revisar y evaluar las propuestas de reforma del SFI, cuyo conjunto se denomina la "Nueva Arquitectura Financiera Internacional". En dichas propuestas el papel del FMI -como cuasi-PUI- es central, tanto como objeto de las propuestas como impulsor de ellas. 
Para analizar las distintas propuestas es importante contar con un mapa de las distintas imperfecciones del sistema financiero internacional. Esto se aborda en la sección 2, en que se describen primero las imperfecciones que son comunes al SFI y a un sistema financiero nacional y luego las que son propias al SFI. Ello permite analizar las propuestas realizadas por académicos, participantes de los mercados y las propias IFIs en la sección 3, identificando las imperfecciones que pretenden subsanar. Aquí es importante distinguir entre las propuestas puramente académicas y las que se están implementando en la actualidad. La sección 4 presenta una evaluación, desde el punto de vista de una economía emergente avanzada, de las propuestas de reforma del SFI planteadas o implementadas por el FMI. Comentarios finales son presentados en la sección 5.

\section{Imperfecciones, Arquitectura Financiera Internacional y PUI: Aspectos Conceptuales}

Las múltiples propuestas para reformar la arquitectura financiera internacional intentan mitigar los problemas que ocasionan algunas de las imperfecciones que existen en el sistema financiero internacional. En principio, éste enfrenta dos conjuntos de imperfecciones. Por un lado, por su esencia de sistema financiero, comparte los mismos problemas que sufre un sistema a nivel nacional o local. Por otro, su característica global que relaciona estados soberanos genera complicaciones que no están presentes a escala local y/o amplifica los efectos de imperfecciones que pueden existir dentro de un mismo país.

Desde el punto de vista de este trabajo, las implicancias de las imperfecciones en un mercado financiero, sea este local o global, son una asignación posiblemente ineficiente del financiamiento (incluyendo un exceso de financiamiento de algunos proyectos e insuficiente en otros) y, más importante aún, una eventual mayor probabilidad de ocurrencia de crisis o la materialización de crisis más profundas. Entendemos como crisis a aquellos eventos en que existe abruptamente un problema de elevada escasez en la cuenta de capitales de la unidad bajo estudio, sea este un país o una firma, incluido un intermediario financiero. Especial interés tienen las crisis que se originan por problemas de liquidez, esto es, que ocurren en unidades que podrían ser solventes -y evitar la crisis- si tuvieran acceso a financiamiento. A nivel internacional, además, las crisis de liquidez a menudo incluyen un problema de corrida contra la moneda.

Las imperfecciones del SFI no son académicas ni triviales. Se manifiestan en una sucesión de crisis financieras internacionales que han sido crecientes (México en 1994, Asia en 1997, Rusia en 1998, Brasil en 1999, Argentina en 2001). Más aún, constituyen episodios que tienen grandes costos reales para los países que las sufren y, en la mayoría de los casos, fuertes pérdidas para inversionistas internacionales. Sus consecuencias tienden a ser más negativas cuando involucran tanto al sistema financiero de un país como a su balanza de pagos (Kaminsky y Reinhart, 1999). La frecuencia y gravedad de las crisis ha llevado tanto a tratar de identificar sus causas (las imperfecciones analizadas en esta sección) como a un 
explosivo aumento en propuestas de solución, que se analizan con más detalle en las secciones siguientes.

Una forma de mitigar las crisis de liquidez es implementar sistemas que proporcionen fondos en casos especiales. En el límite, cuando la entidad encargada de este procedimiento tiene suficientes recursos, se le denomina PUI. Aunque la lógica detrás de su existencia es similar, existen algunas diferencias importantes entre un PUI a nivel local e internacional. Quizá la más importante es que a nivel local existe la posibilidad de que el PUI tenga la posibilidad de cobrar impuestos y emitir dinero. Esto implica que las limitaciones de recursos pueden ser muy diferentes a nivel local y global, incluso que las facilidades que existan a nivel global no sean estrictamente un PUI. Otra diferencia central entre un PUI nacional y un PUI internacional es que el segundo (al menos el FMI) en principio no transfiere recursos netos en valor presente a los países que asiste.

También es posible mitigar la probabilidad o gravedad de una crisis, sea esta de liquidez o de solvencia, a través de políticas adecuadas por parte de los agentes deudores. A nivel de un sistema financiero local, existen regulaciones prudenciales que inciden en el comportamiento de los intermediarios. A nivel global, existen políticas que se consideran más o menos adecuadas, una vigilancia de ellas por parte de organismos multilaterales, y en el extremo, condicionalidad en el acceso a ciertos programas. De hecho, es a veces posible sortear un problema de solvencia si se implementan políticas apropiadas. Muchas veces un PUI adopta el rol de regulador o supervisor sobre las políticas. A nivel internacional, las recomendaciones del FMI y la condicionalidad que incluyen los programas tienen esta característica.

En lo que sigue en esta sección, se analizan distintas imperfecciones de los mercados de capitales, cómo un PUI puede mitigar algunas de sus implicancias y las propias imperfecciones que genera su existencia. Se presenta una taxonomía de imperfecciones (resumida en el Cuadro 1), que es útil para este trabajo, pero que no constituye un ordenamiento definitivo de la literatura de crisis, sino más bien una revisión selectiva de las imperfecciones del mercado y sus consecuencias. ${ }^{1}$

2.1. Imperfecciones comunes a sistemas financieros nacionales y al sistema financiero internacional

Entre las imperfecciones que comparten un sistema local y global están (i) la información asimétrica que existe entre deudores y acreedores, incluyendo la imposibilidad de verificar completamente los resultados y la información privada sobre características no observables de proyectos y agentes; (ii) la existencia de la responsabilidad limitada o de restricciones al establecimiento de garantías o de colateral; (iii) la implementación de políticas por parte del deudor que pueden ser inadecuadas, que son inciertas o inconsistentes desde el punto de vista 
intertemporal; (iv) el riesgo de contagio entre distintas unidades financieras; y (v) los problemas de riesgo moral que genera la presencia explícita o implícita de garantías extendidas por un PUI (u otro diseño de ese tipo en caso que los recursos disponibles no sean suficientes para denominarse PUI).

\section{CUADRO 1}

IMPERFECCIONES DEL SISTEMA FINANCIERO INTERNACIONAL

\begin{tabular}{lll}
\hline \multicolumn{2}{c}{ Comunes a todos los sistemas financieros } \\
\hline \multicolumn{2}{c}{ Imperfección } & \multicolumn{1}{c}{ Posible Consecuencia } \\
\hline 1. & \multicolumn{1}{c}{ Descalce entre madurez de proyectos y } \\
financiamiento & Hace posible una crisis de liquidez \\
a) Asimetrías de información & \\
b) Responsabilidad limitada y dificultad de & establecer/mover el colateral \\
c) Calidad incierta de las políticas & Aumenta la probabilidad de una crisis de \\
2. Políticas inadecuadas por parte del deudor & solvencia \\
3. Comportamiento de manada e & Hace posible el contagio \\
imperfecciones de información & Refuerza las posibilidades de 1 y 2 \\
\hline
\end{tabular}

Exclusivos en el sistema financiero internacional

$$
\text { Imperfección }
$$

Posible Consecuencia

5. Derivados de la existencia de soberanía:
a) Ausencia de procedimiento internacional de bancarrota
Aumenta probabilidad y amplifica crisis

b) Separación entre voluntad y capacidad de pagar solvencia bancarrota

c) Fragilidad de régimen cambiario

d) Falta de coordinación entre acreedores

6. Derivados de las características del PUI

internacional:

a) Recursos limitados

Aumenta probabilidad y amplifica crisis

Hace posible una crisis melliza

Aumenta la probabilidad y amplifica las crisis

Hace más probable una crisis de liquidez y el contagio

b) Dificultades para separar insolvencia de iliquidez

c) Débil gobernabilidad

Aumenta la probabilidad y amplifica la crisis

Hace más probable una crisis de liquidez y el contagio

Las tres primeras imperfecciones (existencia de información asimétrica, responsabilidad limitada y calidad incierta de las políticas) reducen el abanico de contratos disponibles. Esto, por una parte, limita el acceso al financiamiento, pudiendo incluso desaparecer. Por otra parte, de existir financiamiento, éste tiende a estructurarse de manera más precaria, haciendo vulnerable la situación del propio deudor. Por ejemplo, se concentra en plazos cortos o los flujos se hacen menos adaptables a los resultados del proyecto. Un problema general es la existencia de un descalce entre la madurez de los proyectos que se necesita financiar y la del financiamiento disponible.

La estructuración de algunos contratos abre la posibilidad para que existan "corridas", es decir, equilibrios en que, a pesar de que una unidad es solvente desde una perspectiva intertemporal, enfrenta un problema de iliquidez que la termina llevando a la quiebra (o la torna insolvente desde la perspectiva ex post). 
En particular, en el caso de bancos con reserva fraccional, es bien sabido que puede existir una corrida en la que se "destruye riqueza" porque involucra cancelar proyectos que son en realidad rentables si no se interrumpieran. En vista de la fragilidad de algunos contratos, específicamente aquéllos de renta fija suscritos por parte de deudores cuyos activos (o proyectos) sufren de algún grado de iliquidez, muchas economías han dispuesto la existencia de un PUI, típicamente el banco central. Este agente puede entregar amplia liquidez al sistema financiero nacional en momentos en que lo requiera, de manera de limitar una crisis de liquidez.

La implementación de políticas inadecuadas puede, además de limitar el tipo de contrato disponible, gatillar tanto una crisis de liquidez como una de solvencia. Aun cuando en equilibrio es esperable que existan algunas crisis de solvencia -pueden darse estados de la naturaleza especialmente adversos- la coherencia de las decisiones de política influyen en cuán probable y grave es una situación de esta naturaleza. Clave para que este problema sea relevante desde el punto de vista de la estabilidad financiera es que la calidad de las políticas no sea perfectamente predecible. Si este fuera el caso, no existirían inconvenientes para que el monto de financiamiento mismo o su costo reflejara adecuadamente los riesgos envueltos. Ex ante, sin embargo, no es posible para el acreedor conocer las decisiones futuras del deudor, sea éste un deudor final o un intermediario. Así, políticas inadecuadas de manejo de liquidez, una administración que tome riesgos excesivos o decisiones de política que no tienen la coherencia requerida pueden generar un problema de solvencia o facilitar una corrida.

La existencia de un PUI toma aún mayor relevancia cuando existe el riesgo de contagio, eso es, situaciones en que un problema de liquidez específico a una institución amenaza la estabilidad de otras unidades o del sistema completo. La diseminación desde una unidad a otra puede ocurrir a través de encadenamientos directos entre unidades, el comportamiento de manada de parte de los acreedores o por la mera posibilidad de que se manifiesten equilibrios de corrida donde ellos puedan existir, incluyendo el proceso de aprendizaje que generan las crisis en un mundo de información imperfecta. En principio, la presencia de un PUI soluciona tanto la crisis de iliquidez de una unidad específica como el contagio que de ella se deriva.

Sin embargo, el diseño de un PUI es en la realidad un asunto complejo. Si bien existen algunos principios generalmente reconocidos, como que el PIU debería proveer toda la liquidez que sea necesaria a una tasa de interés castigada a agentes con buen colateral, evaluado este último bajo condiciones de normalidad, su aplicación no está exenta de dificultades. De partida, evaluar si el colateral es adecuado no es algo obvio, pues supone la capacidad de distinguir, con alguna claridad, insolvencia de iliquidez. ${ }^{2}$ A su vez, no existe una visión única respecto supuestos que se realicen, por lo que determinar cuándo existe insolvencia, y si ella existe, cuál es su magnitud, es una tarea extremadamente difícil. 
de que si un PUI debe otorgar liquidez exclusivamente al sistema como un todo, de manera que éste evalúe la eventual solvencia de una unidad en problemas, o si debe entregar esta liquidez directamente a la unidad bajo estrés. Asimismo, si bien es necesario que un PUI tenga recursos suficientes para inyectar liquidez, tampoco existe consenso respecto de que deba invariablemente tener la capacidad de emitir dinero.

Lo que sí es relativamente evidente es que la presencia de un PUI provoca problemas de riesgo moral, lo que se manifiesta en que tanto deudores como acreedores toman riesgos excesivos, y, por lo tanto, hay más casos de insolvencia que lo socialmente óptimo. En efecto, la existencia de un PUI o, más en general, de garantías que limitan las pérdidas que pueden sufrir los acreedores, hace que se reduzcan los incentivos para un monitoreo apropiado. En el extremo, las acciones de los deudores pueden llegar a ser irrelevantes para las decisiones de los acreedores, lo que distorsiona la asignación de recursos y reduce la disciplina que enfrentan los deudores. En un ambiente de este tipo es probable que la calidad de las políticas se deterioren. El riesgo moral, en todo caso, puede mitigarse a través de reglas de comportamiento del PUI y con regulación y supervisión a los deudores.

2.2. Sistema financiero internacional: Amplificación de las imperfecciones de los sistemas nacionales e imperfecciones adicionales

Como se comentó, a nivel global se amplifican varias de las imperfecciones que existen localmente. En efecto, es probable que las asimetrías de información entre acreedores y deudores sean aún mayores a escala global, limitando todavía más el abanico de contratos disponibles. Por ejemplo, no existe un estándar único de medición y difusión de información. Y si existiera, tampoco es obvio cómo se exige a nivel internacional, considerando la presencia de distintas unidades soberanas.

Por su parte, la responsabilidad limitada, que a nivel local pone un límite a la posibilidad de requisar activos, es más compleja a nivel global. Las dificultades de "transportar" el colateral desde un país a otro hacen que la responsabilidad limitada sea una restricción activa. Más aún, la soberanía implica que existe una separación entre la capacidad de pagar y la disposición a pagar (asunto que está además relacionado al problema de asimetrías de información).

También es posible argumentar que el contagio puede ser más vigoroso a nivel global. Si bien la noción de contagio se aplica a bancos a nivel local y a países a nivel global, es posible conceptualizarlo en ambos casos como el estrés que sufre una unidad aparentemente no relacionada a una unidad en crisis. Más aún, tanto para bancos como para países es posible construir explicaciones para el contagio, basadas en la existencia de equilibrios múltiples que están habitualmente presentes o se vuelven posibles (probables) en escenarios de fundamentales deteriorados. Sin embargo, la existencia de un PUI relativamente más débil a nivel internacional, vis-à-vis uno nacional, podría explicar una mayor propagación del 
contagio a nivel global. Esta relativa debilidad se puede originar porque el PUI internacional enfrenta restricciones de recursos (e.g., no emite dinero) o por problemas de coordinación a nivel de toma de decisiones en el organismo encargado. La presencia de mayores grados de información asimétrica, así como la interrelación que general el comercio internacional, también podrían significar una mayor presencia de contagio a nivel global.

Se ha argumentado también que la gran diversidad de agentes involucrados a nivel global, en comparación con un país particular, podría agravar el problema del riesgo moral que existe bajo cualquier arreglo que provea liquidez en tiempos de estrés. En efecto, a nivel global existen vínculos más lejanos entre quien toma decisiones de inversión, la organización que actúa como PUI y los agentes que eventualmente sufren las consecuencias del riesgo moral (los países en crisis y los que aportan fondos para solventar el PUI).

El riesgo moral a nivel global también puede ser mayor que a nivel local porque en la práctica es imposible organizar un PUI internacional que opere exclusivamente a través de operaciones de mercado abierto, con inyección de liquidez al sistema como un todo. Esta situación, en cambio, puede ocurrir a nivel local, caso en el cual es el mercado el que a fin de cuentas asigna la liquidez entre distintas unidades. En principio, el screening del mercado permite separar mejor los problemas de liquidez de los de solvencia, limitando el riesgo moral. Sin embargo, la mayor escasez relativa de recursos disponibles al PUI internacional es un factor que puede reducir el riesgo moral a nivel internacional.

La presencia de estados soberanos a escala global también genera una serie de problemas que no están presentes a nivel local. De partida, el hecho de que existan unidades independientes (países) con su propio sistema judicial impide que existan procedimientos que administren una bancarrota, incluyendo métodos eficientes para requisar activos y procedimiento de coordinación de los acreedores (por ejemplo, para evitar que se bloquee un acuerdo entre deudor y una mayoría sustancial de acreedores). Ex ante, esta ausencia de procedimientos de bancarrota dificulta el acceso al mercado de capitales. Ex post, en caso de crisis, habitualmente hace que los países sufran costos más elevados y por un mayor tiempo en comparación al resultado de una reestructuración ordenada y oportuna.

La soberanía además refuerza las asimetrías de información, generando un concepto que se encuentra solamente en relaciones internacionales: la distinción entre capacidad de pago y disponibilidad a pagar. En efecto, la inexistencia de una corte internacional para la bancarrota hace que las restricciones de compatibilidad de incentivos se satisfagan con mecanismos menos eficientes que a nivel local. Existe, además, la posibilidad de cambios en el régimen de políticas en los países, así como cambios en el régimen político mismo. En el primer caso, innovaciones hacia esquemas de política incoherentes pueden fácilmente gatillar una crisis. De ahí la necesidad de que las instituciones internacionales vigilen las políticas de los países, incluso que exista condicionalidad para el acceso a los recursos de un PUI. En el segundo se puede complicar la identificación intertemporal del deudor. 
A las características anteriores del sistema financiero internacional se suma la posibilidad de que existan regímenes cambiarios inflexibles, que pueden condicionar la estructura de los contratos y aumentar la vulnerabilidad de los deudores. En sistemas rígidos pueden ocurrir las llamadas crisis mellizas, esto es, una crisis de liquidez simultánea a nivel de intermediarios locales y de balanza de pagos.

Un caso particular de problemas que surge por la ausencia de una corte internacional a nivel global es la dificultad de coordinar acreedores para reestructurar pasivos. Se ha sugerido que esto podría llevar a que una crisis, una vez declarada, sea más profunda porque se alargarían innecesariamente los períodos de estrés a los que se ve sometido un país.

Por último, más allá de tener recursos limitados para operar, la efectividad de un PUI internacional puede ser menor a la de uno local porque enfrenta dos dificultades adicionales. Primero, las asimetrías de información, esta vez entre el PUI y la unidad en crisis, son probablemente mayores a nivel global, lo que dificulta separar casos de insolvencia de casos de iliquidez. La información no fluye de la misma manera entre agentes locales, que pertenecen a una misma jurisdicción, que entre unidades que pertenecen a distintos países. A esto se agrega un problema ex post, en que la comunidad internacional puede verse atraída a condonar obligaciones de países altamente endeudados a través del PUI.

Segundo, la presencia de distintas unidades soberanas a cargo del PUI internacional dificultan la coordinación en la toma de decisiones. La gobernabilidad de instituciones que tienen esta misión tiende a ser menos eficiente a nivel global que local. En particular, se requieren procesos de consulta que no están presentes cuando se trata de un país individual.

\section{Revisión de las Principales Propuestas de Reforma del Sistema FINANCIERO INTERNACIONAL}

Durante la última década se ha formulado un gran número de propuestas para reformar el SFI y corregir sus imperfecciones, en un amplio rango que se extiende desde planteamientos exóticos y parciales hasta planes realistas y globales. Muchas propuestas se han quedado en el plano académico, mientras que otras se están implementando actualmente.

Una forma de analizar las propuestas es en las tres dimensiones en que son presentadas en frecuentes discusiones y documentos oficiales (véase, por ejemplo FMI 2003): las propuestas orientadas a una mejor prevención de crisis financieras, las que propugnan una mejor resolución de las crisis y las que proponen mejorar el rol de PUI internacional jugado por las IFIs, particularmente el FMI.

A continuación se analizan las propuestas más destacadas en estas tres dimensiones y se relacionan con las imperfecciones del SFI que ellas pretenden corregir. En el Cuadro 2 se resumen las propuestas en las tres dimensiones señaladas. Dicho cuadro también distingue entre las propuestas que envuelven al PUI 


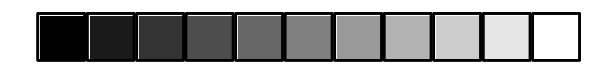

$\phi$

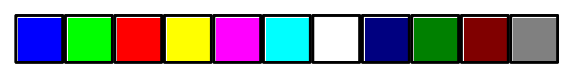

CRISIS FINANCIERAS INTERNACIONALES

369

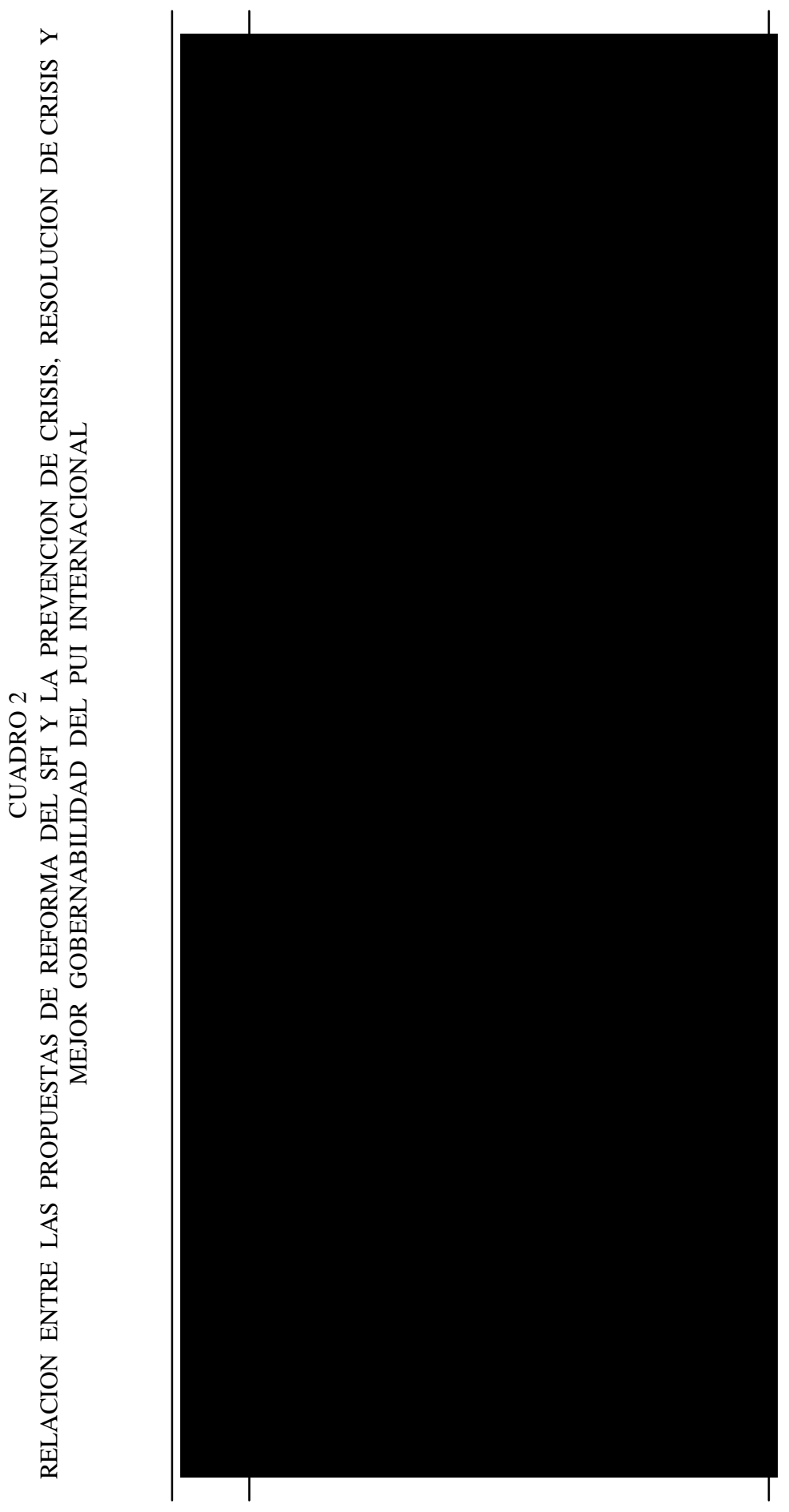

$\phi$ 


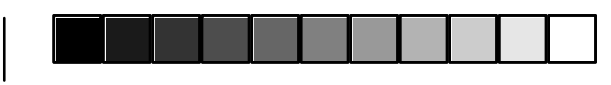

$\phi$

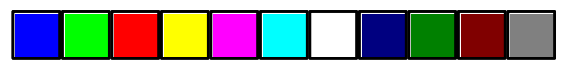

370

CUADERNOS DE ECONOMIA (Vol. 40, No 120, Agosto 2003)

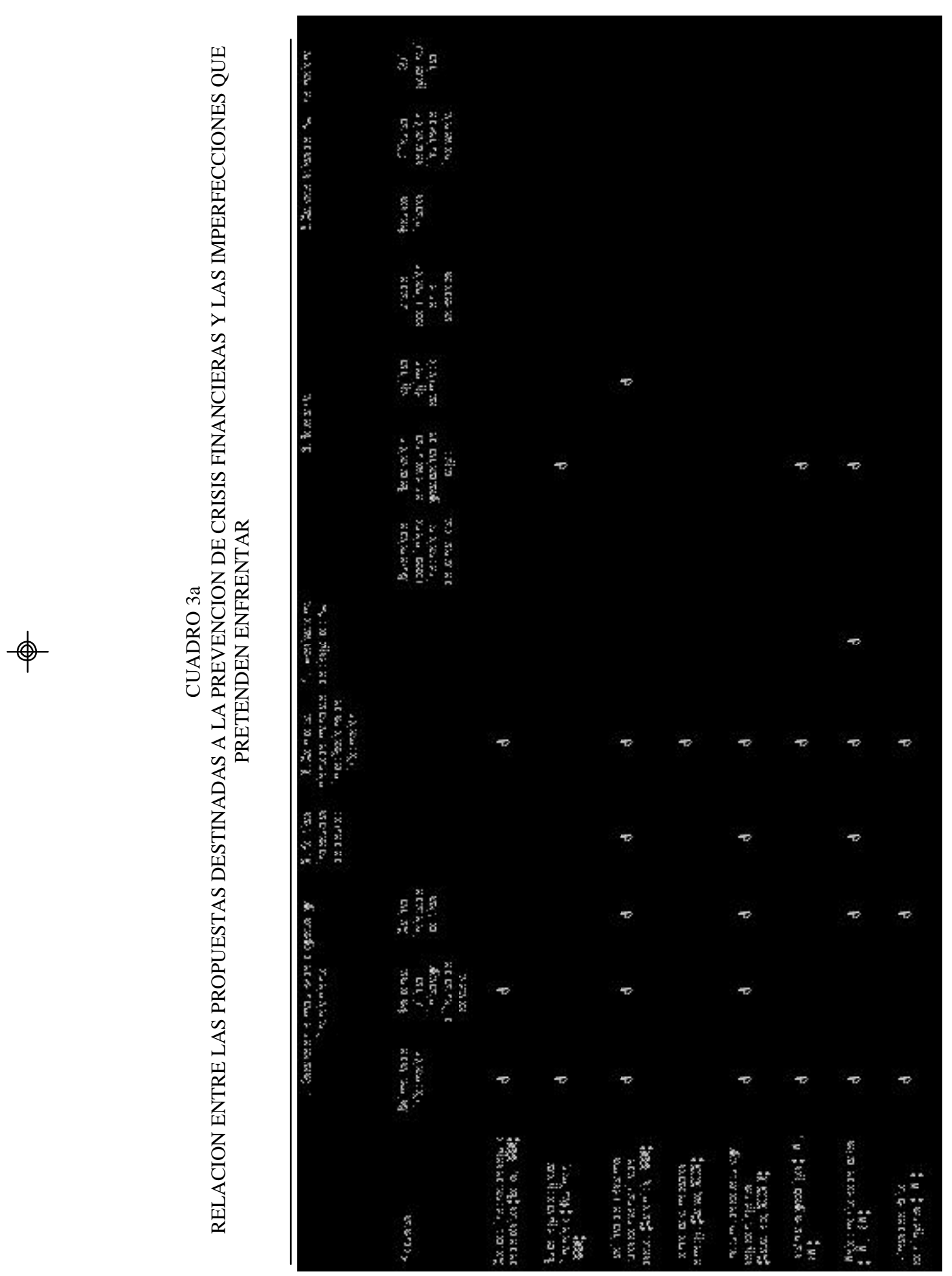

$\varnothing$ 


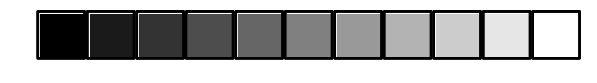

$\Phi$

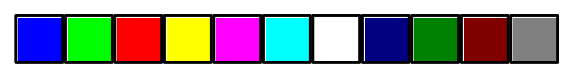

CRISIS FINANCIERAS INTERNACIONALES

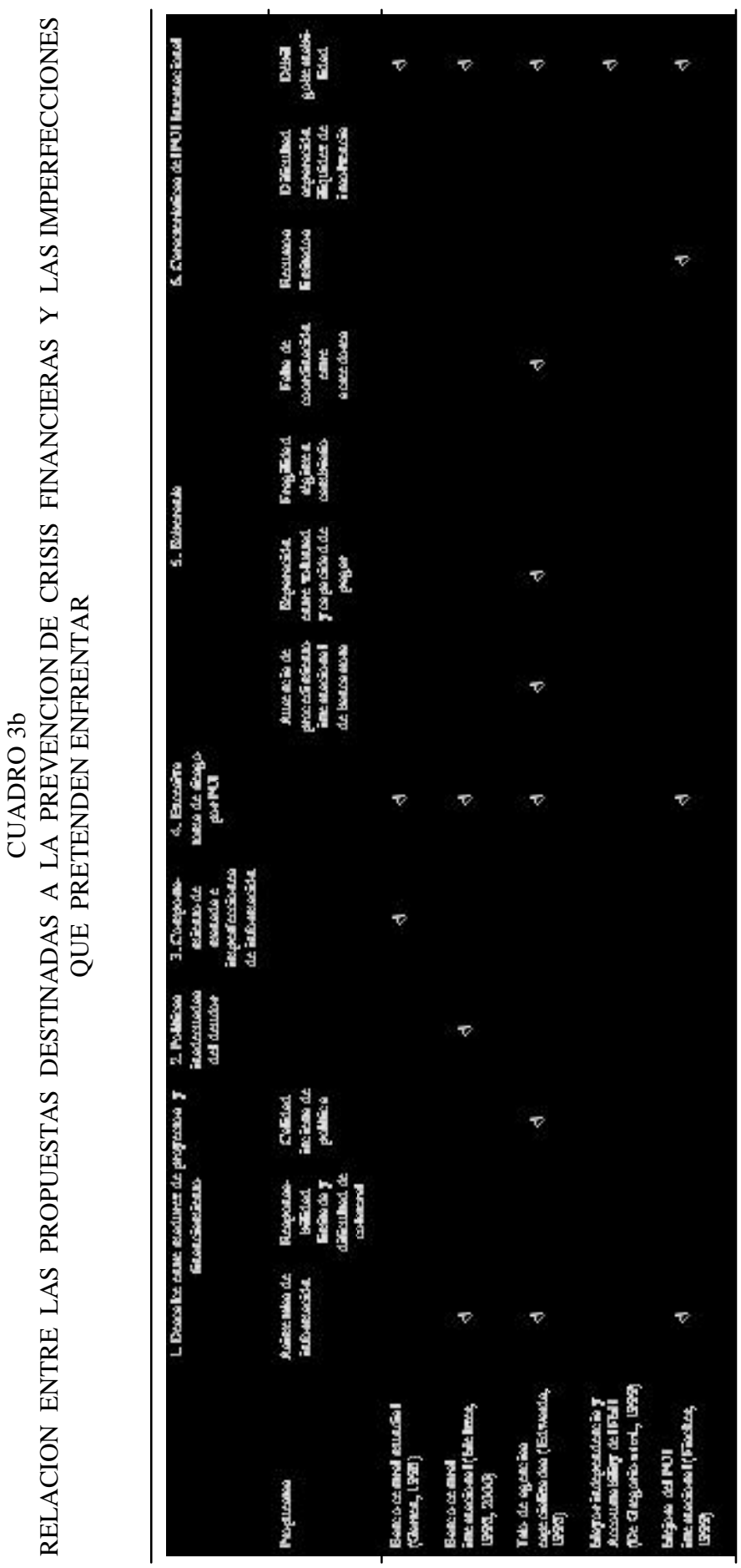

$\oint$ 


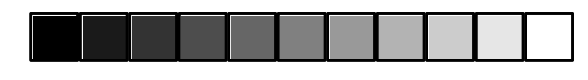

$\phi$

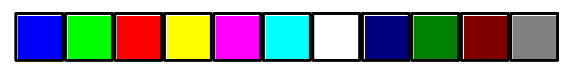

372

CUADERNOS DE ECONOMIA (Vol. 40, $N^{\circ} 120$, Agosto 2003)

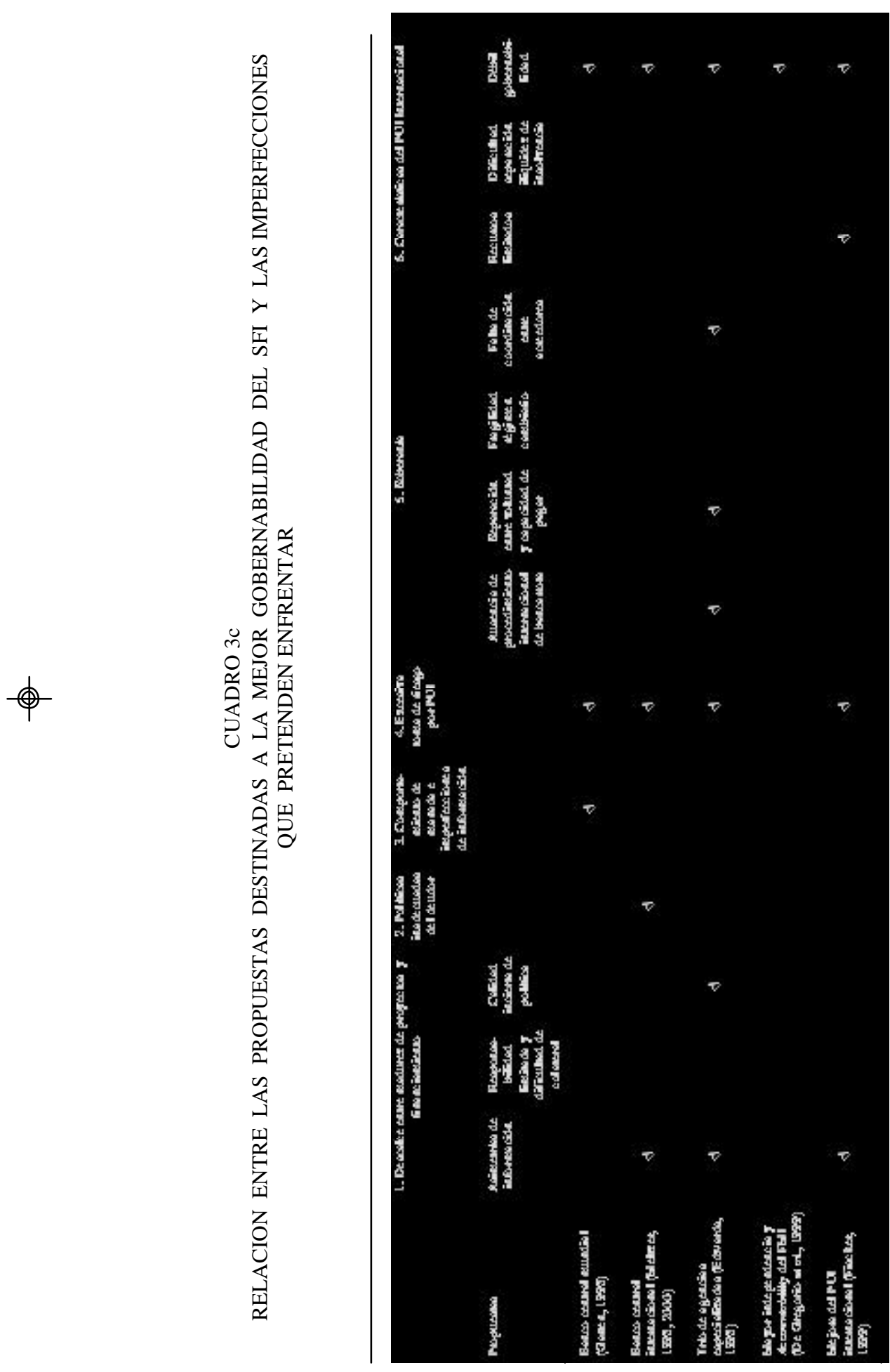

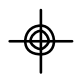



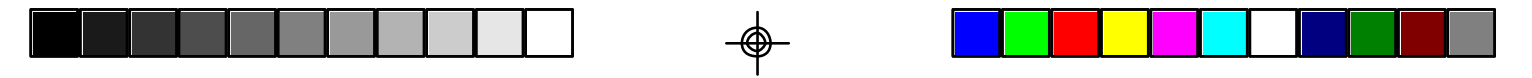

CRISIS FINANCIERAS INTERNACIONALES

(en particular, al FMI) y las que son independientes de él. ${ }^{3}$ De ahí se desprende que la gran mayoría de las reformas propuestas tienen implicancias para el ejercicio del PUI internacional. En el Cuadro 3 se cruzan las propuestas con aquellas imperfecciones del SFI (identificadas en la sección 2) que más directamente cada propuesta podría corregir o atenuar.

\subsection{Prevención de crisis}

Para reducir la probabilidad de ocurrencia de futuras crisis financieras en países individuales o crisis sistémicas, se han planteado múltiples propuestas para reformar el SFI. Iniciamos la revisión de las propuestas que se han quedado en el papel, para continuar con las que se están adoptando en tiempos recientes.

Corporación Internacional de Seguro de Depósitos. Soros (1997, 1998) propone establecer una corporación pública que proveería un seguro a inversionistas internacionales ante la ocurrencia de repudios de deuda soberana. Las características de este seguro serían: (i) los países miembros pagan una prima de seguro, (ii) el FMI, de acuerdo a las condiciones macroeconómicas y financieras del país, establece niveles máximos de montos a asegurar para cada país, y (iii) los montos de deuda por encima de dicho límite no serían asegurados. Esta propuesta apunta a reducir la probabilidad de una crisis de liquidez (reduciendo asimetrías de información y mejorando el colateral) y a aminorar la probabilidad de efectos manada e imperfecciones de información (causantes de contagio). Sin embargo, como involucra el establecimiento de un seguro de depósito, puede incrementar el riesgo moral por la garantía, llevando a sobreendeudamiento.

Suprarregulador Global de Mercados e Instituciones Financieras y Agencia de Rating. Kaufman (1998) propone el establecimiento de una entidad suprarreguladora internacional, encargada de: (i) supervisar las actividades de inversión y toma de posiciones de intermediarios financieros tradicionales y otros participantes del mercado financiero, y (ii) armonizar requerimientos mínimos de capital, contabilidad uniforme y monitoreo. Además, Kaufman plantea la creación de una agencia de evaluación de riesgo (Rating Agency) que provea de ratings públicos de calidad de crédito de los mercados e instituciones de sus miembros. Esta propuesta, que no envuelve al PUI internacional, permitiría reducir las asimetrías de información y elevar la voluntad de pago de los deudores.

Facilidad de Préstamos Limitados a través de una Ventanilla de Descuento (Limited Discount Window Lending Facility). Calomiris (1998) reemplaza-

Cabe advertir que la clasificación de propuestas de acuerdo con las tres dimensiones mencionadas es algo arbitraria, porque varias propuestas pueden aportar tanto a la mejor prevención como a la resolución de crisis y a perfeccionar el papel jugado por el PUI internacional. 
ría al actual FMI y al Fondo de Estabilización Cambiaria de EE.UU. (US Exchange Stabilization Fund) por un FMI reformado que ofrecería una línea de crédito a una tasa de interés con penalidad y sólo por periodos cortos. Dicha facilidad financiera estaría disponible para los miembros del FMI y la membresía obligaría a los países a: (i) exigir a su banca a que mantenga montos significativos de capital y emita deuda subordinada, (ii) extender seguros de depósito a otros instrumentos de deuda bancaria, (iii) imponer requerimientos de liquidez mínimos (20\% de activos en efectivo o equivalente y $20 \%$ de activos en valores líquidos), (iv) permitir la libre entrada a la banca nacional y extranjera, (v) limitar ayuda fiscal a la banca, (vi) hacer que la banca ofrezca cuentas bancarias en moneda nacional y extranjera, (vii) exigir reservas bancarias adicionales si el régimen cambiario es fijo, y (viii) exigir que el gobierno siga ciertas prácticas de manejo de deuda, tales como imponer límites al endeudamiento de corto plazo. Los miembros de este FMI reformado brindarían como colateral bonos de gobierno. Esta propuesta podría reducir la probabilidad de crisis de liquidez (minimizando asimetrías de información, mejorando el colateral y la calidad de las políticas económicas) y de comportamientos de manada e imperfecciones de información evitando, a su vez, políticas inadecuadas de parte del deudor. Además limitaría los problemas derivados de la soberanía, limitando el ejercicio de las políticas domésticas.

Fondo para Mercados Emergentes. Calvo (2002) propone la formación de un fondo para estabilizar un índice de precios de activos de economías emergentes (por ejemplo, el índice de precios de deuda soberana JP Morgan Chase EMBI+). Este fondo internacional debería estar preparado para poder comprar bonos de otras economías emergentes y así evitar el colapso de sus precios. Este fondo estaría financiado con instrumentos de deuda aportados por los G-3 y decidiría caso a caso cuando es apropiado intervenir en los mercados. No sería objeto del fondo otorgar liquidez a un país en crisis, debiendo sólo intervenir en el mercado internacional de deuda soberana para evitar comportamientos de manada e imperfecciones de información, con el consiguiente contagio hacia terceros países.

Instrumentos de Cobertura y Seguro Contingentes. Caballero (2002, 2003) propone la creación de instrumentos de seguro y cobertura ante posibles reversiones de flujos de capitales. Las IFIs, o eventualmente el banco central de la economía emergente, deberían colaborar en: (i) identificar la base contingente contractual del país y desarrollar el correspondiente instrumento contingente a un estado de naturaleza adverso predefinido, (ii) crear y regular un fondo de contingencia para economías emergentes, y (iii) diseñar un marco de política macroeconómica consistente con este mecanismo de aseguramiento, y monitorear su ejecución. Esta propuesta contribuiría a reducir la probabilidad de crisis de liquidez y a prevenir efectos manada e imperfecciones de información, reduciendo también los problemas derivados de políticas inadecuadas del deudor y la soberanía nacional.

Cabe destacar que la mayoría de las propuestas académicas anteriores, estando fundamentalmente orientadas a la prevención de crisis financieras, tam- 
bién redefinen en alguna dimensión las tareas del PUI internacional y del FMI en particular. En las propuestas que siguen, esta redefinición de tareas para las IFIs es más importante aún, tratándose de propuestas activamente promovidas por las IFIs en general y por el FMI en particular.

Adopción de estándares y códigos internacionales. El desarrollo y la adopción de estándares y códigos reconocidos internacionalmente es primordial para mejorar la capacidad institucional de todos los países y mejorar la evaluación de riesgo de mercados financieros. Desde 1996, y en mayor grado en años recientes, el FMI y el BM están apoyando activamente la adopción de estándares y códigos universales en 12 áreas centrales. ${ }^{4}$ Esta globalización de la información, los estándares y los procedimientos a todos los países del mundo tiene grandes beneficio para la transparencia y comparabilidad de datos, políticas e instituciones, contribuyendo a reducir las asimetrías de información entre deudores soberanos y acreedores, comportamientos manada e imperfecciones de información, el riesgo moral y los problemas derivados de la soberanía nacional en códigos y estándares.

Mejor monitoreo de países por las IFIs. Las IFIs, y particularmente el FMI, están mejorando sustancialmente la cobertura y profundidad del monitoreo de los países miembros y los mercados financieros internacionales. El mejor monitoreo incluye un seguimiento más cercano de las economías individuales y los mercados financieros internacionales, la asistencia técnica a las reformas macroeconómicas y estructurales (particularmente de los sistemas bancarios y mercados de capitales nacionales), la publicación de los informes de países preparados por las IFIs, las evaluaciones de sostenibilidad de deuda externa y de vulnerabilidades a crisis financieras para países individuales, entre otras medidas. El mejor monitoreo contribuye a reducir las asimetrías de información, las políticas inadecuadas del país deudor, los efectos manada e imperfecciones de información, la excesiva toma de riesgo del PUI, y a aumentar la capacidad y voluntad de pago de los deudores.

Líneas de Crédito Contingentes (CCL o Contigent Credit Lines). Aprobadas en 1999 y modificadas en el 2000 por el FMI, como un nuevo instrumento 
financiero en apoyo a países con buenos fundamentos, pero susceptibles de contagio en un contexto de turbulencia financiera internacional. Consisten en un seguro de liquidez o facilidad preventiva diseñada para países miembros del FMI que cumplan con (i) no tener la necesidad de préstamos del FMI salvo para afrontar un problema transitorio de contagio, (ii) una evaluación positiva de políticas y avance hacia la adopción de estándares internacionalmente aceptados, (iii) relaciones constructivas con acreedores privados y progreso hacia la limitación de la vulnerabilidad externa, y (iv) un programa macroeconómico y financiero satisfactorio y el compromiso de ajustar políticas cuando sea necesario (ver FMI, 2001). Otras características de las CCL son: el compromiso de los fondos es por un año, desembolso inmediato de una primera parte al ser aprobado el préstamo, período de repago entre 12 y 18 meses, tasas de interés inferiores a las de otras facilidades del FMI. Los beneficios potenciales de esta provisión de liquidez incluyen una reducción de las asimetrías de información, menor posibilidad de comportamientos manada e imperfecciones de información y una mejor calidad de las políticas en virtud de la condicionalidad de las CCL. Hasta la fecha ningún país ha decidido participar en el programa de CCL. En la sección 4 se analizará la razón de este resultado, en el marco de la evaluación global de las CCL para economías emergentes de frontera.

\subsection{Resolución de crisis}

Las propuestas para mejorar la resolución de crisis financieras, una vez que se han declarado, también pueden dividirse entre las de origen más académico y aquéllas que son promovidas activamente por el FMI. Iniciamos esta revisión con las primeras. Cabe destacar, además, que la mayoría de las propuestas de resolución de crisis se hacen para los casos en que se estima que la deuda soberana es insostenible, vale decir, se trata de situaciones de insolvencia externa que, de no recibir un tratamiento eficiente, pueden llevar a costos elevados y prolongados, derivados de la consiguiente moratoria o repudio del servicio de deuda e imposibilidad de acceso al mercado privado de capitales.

Tribunal de Bancarrota Internacional. Con el fin de proveer un procedimiento internacional de bancarrota y mejorar la coordinación entre acreedores, Raffer (1990) propone el establecimiento de un tribunal de bancarrota a nivel internacional, que imponga una pausa en caso de crisis financiera y términos de arreglo entre deudores y acreedores que no son capaces de ponerse de acuerdo en una reestructuración voluntaria. Este esquema está inspirado en los capítulos 9 y 11 de la ley de bancarrota de los EE.UU., con las diferencias sustanciales de que el tribunal propuesto: (i) tendría carácter internacional, (ii) estaría localizado en un país neutral (ni en un activo prestamista ni en un importante prestatario internacional), y (iii) estaría dotado de poder para imponer los términos de arreglo entre deudores y acreedores cuando no sean capaces de llegar a una reestructuración 
de forma voluntaria. Sachs (1995) propone un esquema similar, agregando el poder de emitir nueva deuda para capital de trabajo. Esta propuesta, que no envuelve al PUI internacional, apunta fundamentalmente a corregir la ausencia de un procedimiento internacional de bancarrota, pero también contribuiría a una mejor coordinación entre acreedores.

Cuasi PUI Internacional. Lerrick y Meltzer (2001a,b) proponen establecer un mecanismo de reestructuración financiera en caso de un repudio de deuda "constructivo", es decir, cuando deudores y acreedores renegocian ordenadamente la deuda. ${ }^{5}$ Los pasos a seguir serían: (i) se suspenden los pagos en moneda extranjera al sector privado, (ii) se reestructura la deuda en un plazo de 3 meses sobre un mínimo valor de reestructuración, (iii) el país entra en un acuerdo con el PUI internacional, a manera de ventanilla de descuento internacional, en la que el PUI compraría con descuento la deuda del país en crisis. Esta propuesta proveería un procedimiento de bancarrota internacional (como las propuestas de Raffer y Sachs) y también otorgaría un rol de compra de deuda soberana a una institución internacional, pero, a diferencia de la propuesta de Calvo, concentraría dicha compra de deuda en el país en crisis, no en la periferia contagiada. Esta última característica tiene la desventaja que incrementaría comportamientos de riesgo moral. Al igual que la propuesta de los primeros, ésta corregiría la ausencia de un procedimiento internacional de bancarrota y contribuiría a una mejor coordinación entre acreedores

Condicionalidad endurecida de los préstamos de las IFIs. El FMI ha endurecido la condicionalidad para la provisión de recursos elevados a países en crisis de cuenta de capitales, requiriendo el cumplimiento de cuatro condiciones (FMI 2003): (i) la existencia de presiones excepcionales sobre la cuenta de capitales, (ii) solvencia externa reflejada en un peso de deuda estimado como sostenible, (iii) buenas perspectivas de reacceso al mercado de capitales privados en un plazo breve, y (iv) acuerdo sobre un programa de ajuste vigoroso, con señales claras de que el gobierno tendría la voluntad y capacidad de cumplir el programa de ajuste. Esta propuesta de endurecimiento de la condicionalidad tradicional de asistencia financiera oficial para países solventes que sufren una crisis de liquidez, ya implementada por el FMI, tiene por objeto reducir la toma de riesgo del PUI internacional (que se asocia a los programas tradicionales de rescate por las IFIs), fortalecer la voluntad, la capacidad de pago y las políticas de los deudores y permitir una mejor distinción de iliquidez e insolvencia por el PUI.

Cláusulas de Acción Colectiva (CAC). Esta propuesta, activamente promovida por el Departamento del Tesoro de EE.UU., apunta al establecimiento de cláusulas en contratos de deuda soberana al momento de su emisión. Además permiten que una determinada supermayoría de tenedores acuerde términos de 
reestructuración del bono con el país deudor, los que serían obligatorios para todos los tenedores de dicha emisión ${ }^{6}$. Estas cláusulas ya han sido incorporadas en emisiones recientes de deuda soberana de varios países en la jurisdicción de Nueva York, como se discutirá en la sección 4. Las CACs tienen como objetivo primordial evitar el bloqueo de un acuerdo de reestructuración por minorías pequeñas de tenedores de bonos, reduciendo además la excesiva toma de riesgo del PUI, forzando, eventualmente, al país deudor a evidenciar una mayor voluntad de pago y permitiendo una mejor distinción entre iliquidez e insolvencia por parte del PUI. Las CACs no involucran al FMI u otro PUI internacional.

Mecanismo de Reestructuración de Deuda Soberana (SDRM o Sovereign Debt Restructuring Mechanism). Esta propuesta del FMI también está inspirada en el capítulo 11 de la ley de bancarrota norteamericana. Esta propuesta proveería un marco normativo para una reestructuración global de la deuda externa de un país, con las siguientes características: (i) una determinada supermayoría de todos los acreedores individuales de distintas emisiones de deuda soberana del país en cuestión vota a favor de los términos de un acuerdo de reestructuración, que serían obligatorios para todos los acreedores del país, (ii) con provisiones que impiden acciones legales por acreedores que interrumpan el proceso de negociación, y (iii) con participación de un foro de resolución de disputas.

La propuesta de SDRM, al igual que las CACs, busca evitar el bloqueo de un acuerdo de reestructuración por minorías pequeñas de tenedores de bonos, reduciendo además la toma de riesgo del PUI y, eventualmente, fuerza al país deudor a evidenciar una mayor voluntad de pago de la deuda y permite una mejor distinción de iliquidez e insolvencia por el PUI. En su última versión (IMF 2003), la propuesta de SDRM no involucra al FMI u otro PUI internacional. Hasta la fecha, los mercados financieros internacionales no han mostrado apoyo a esta propuesta y se ve improbable la aprobación de ella por el directorio del FMI, como se analizará en más detalle en la sección 4.

\subsection{Mejor gobernabilidad del PUI Internacional}

Las propuestas de reforma del PUI internacional incluyen aquéllas que buscan un cambio radical en la institucionalidad del PUI (incluyendo la abolición del FMI y su remplazo por nuevas instituciones) y otras que proponen una reforma del rol de PUI jugado por el FMI hasta la fecha. Cabe notar que muchas de las propuestas para una mejor prevención y resolución de crisis financieras, discutidas arriba, incluían algunas reformas del rol jugado por el FMI como PUI. Aquí se agregan propuestas más radicales, con redefiniciones más importantes del papel de deuda privada y pública, y de una opción para renovaciones de 90 días que los deudores ejecutarían en caso de crisis. 
del PUI internacional. Nuevamente partimos con la discusión de propuestas académicas.

Banco Central Mundial. La propuesta de Garten (1998) consiste en crear un banco central mundial con la capacidad y el mandato para: (i) comprar los instrumentos de los gobiernos miembros mediante operaciones de mercado abierto, (ii) supervisar bancos y otras instituciones financieras, (iii) establecer estándares uniformes para endeudamiento, y (iv) responder a un comité de gobernadores del G-7 y 8 miembros rotantes de economías emergentes. Además, financiaría sus operaciones con líneas de crédito de los bancos centrales de cada país o con un moderado impuesto a las transacciones comerciales o financieras internacionales. Esta propuesta apunta a reducir los problemas que originan comportamientos tipo manada e imperfecciones de información y la toma de riesgo en exceso por parte del PUI, y a mejorar la gobernabilidad del PUI internacional.

Banco Central Internacional. Parecida a la propuesta anterior, Meltzer (1998) propone un "verdadero" PUI internacional que tenga como principal rol limitar los préstamos del FMI (o el BIS) a préstamos de corto plazo, a altas tasas de interés, con colateral sólido y a países con adecuadas políticas macroeconómicas. Los bancos centrales podrían pedir préstamos del FMI solamente presentando activos transables internacionalmente y, por su parte, el FMI estaría limitado a prestar a cambio de colaterales líquidos en el mercado internacional. El FMI podría ser reemplazado por el BIS como banco central internacional. Esta propuesta tiene como objetivo minimizar la toma excesiva de riesgo y mejorar la gobernabilidad del PUI internacional.

Luego, Meltzer (2000) recoge parte de sus anteriores recomendaciones. Así, en su calidad de jefe de la Comisión Asesora de IFIs del Senado norteamericano, el autor resumiría las propuestas de cambio sugeridas por dicha comisión en cuatro: (i) aumentar la transparencia, (ii) mejorar accountability, (iii) reducir la corrupción en países receptores de ayuda financiera, y (iv) aumentar significativamente la efectividad de los programas del FMI y bancos de desarrollo. La Comisión desestimó además la necesidad de que el FMI y los bancos de desarrollo tengan por separado programas de reducción de pobreza, ya que dicha duplicidad reduce el accountability y genera un desperdicio de recursos. Finalmente, se votó unánimemente por restringir al FMI a préstamos de corto plazo y a exigir a los gobiernos los siguientes requisitos: (i) asegurar adecuación de capital de la banca doméstica, (ii) mercado bancario abierto a la competencia extranjera, (iii) compromiso de estándares fiscales, y (iv) garantizar información financiera más temprana y precisa (ver Meltzer, 2000). Tal como está diseñada, esta propuesta tiene como objetivos reducir asimetrías de información, promover políticas adecuadas para los países deudores, minimizar la toma excesiva de riesgo y mejorar la gobernabilidad del PUI internacional.

Trío de Agencias Especializadas. Edwards (1998) propone reemplazar el FMI por tres agencias internacionales especializadas: (i) una agencia de informa- 
ción global (AIG), que proveería de información (oportuna y sin censura) de la condición financiera de los países, de evaluaciones de sus sistemas financieros y "alertas rojas" en caso de que los países no provean adecuada información, (ii) una facilidad financiera global contingente que proveería líneas de crédito contingentes para países con sólidas políticas, pero con problemas temporales de liquidez certificados por la agencia de información global y (iii) una agencia de reestructuración global, que tendría poder para imponer una suspensión de pagos y proveer financiamiento oficial, sujeto a condicionalidad, a países en negociaciones de "buena fe" y que estén realizando esfuerzos realistas de reestructuración. La globalidad de esta propuesta hace que potencialmente contribuya a corregir un gran número de imperfecciones: asimetrías de información, descalce de madurez, excesiva toma de riesgo del PUI, ausencia de procedimientos de bancarrota, separación de voluntad y capacidad de pago, falta de coordinación de acreedores y débil gobernabilidad actual del PUI internacional.

Mayor Independencia y Accountability del FMI. De Gregorioet al. (1999) delinean una serie de propuestas cuyo eje primordial es el proveer de mayor independencia y accountability al FMI. Si bien los autores concuerdan con varios elementos de otras propuestas tales como mejorar la transparencia entre deudores y acreedores, mejorar la provisión de información de parte de los gobiernos, evitar los rescates a países en crisis con cada vez mayores niveles de crédito y promover las reestructuraciones de deuda dentro del funcionamiento del libre mercado, añaden que es necesario que el FMI cambie su proceso de toma de decisiones, haciendo que los directores ejecutivos sean independientes de los gobiernos, pero rindan cuentas al comité interino de las naciones representadas. Esta mayor independencia permitiría al directorio tomar compromisos más creíbles para reforzar las condiciones crediticias, sin rescates automáticos a países en crisis $\mathrm{y}$, a su vez, aislar al directorio de presiones para llevar a cabo las agendas políticas de los gobiernos nacionales.

Esta propuesta se concentra, por lo tanto, en atacar el problema de la débil gobernabilidad del PUI internacional.

Mejora del PUI Internacional. Fischer (1999), el entonces Director Gerente del FMI, propone reforzar el rol del FMI como un PUI internacional otorgando en forma más efectiva facilidades de préstamos, como el Supplemental Reserve Facility (SRF), que sólo ha sido usada por el FMI en los casos de Corea, Rusia y Brasil. Además propone la aplicación de estándares y códigos internacionales, mejoras en transparencia y mayor información relevante de los países miembros, en particular de las economías emergentes. Además, el principal rol del PUI debe ser administrar la crisis, para lo cual no se necesitarían grandes recursos. ${ }^{7}$ Estos planteamientos, recogidos más adelante en las iniciativas propuestas o

Ello, en respuesta a la preocupación de algunos autores acerca de la incapacidad del FMI (como PUI internacional) de emitir dinero y tener suficientes recursos para apoyar a EEs en una crisis (ver, por ejemplo, Calomiris, 1998). 

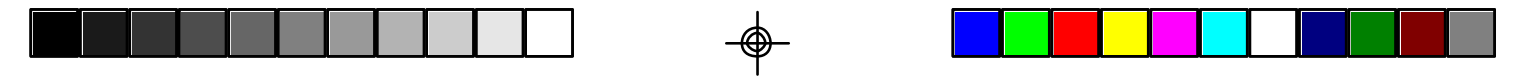

CRISIS FINANCIERAS INTERNACIONALES

implementadas por el FMI y que fueron descritas arriba, apuntan a reducir los problemas de información asimétrica, excesiva toma de riesgo, escasez de recursos del PUI y gobernabilidad del FMI.

\section{Evaluación de las Propuestas Recientes del FMI}

Algunas de las propuestas presentadas en la sección anterior han sido sometidas a significativa discusión en la comunidad financiera internacional en años recientes. Destacan entre éstas las referidas a mecanismos de reestructuración de deuda. También ha recibido un grado relevante de atención la línea de crédito contingente ofrecida por el FMI desde 1999. Esta sección examina y evalúa el estado actual de estas iniciativas, desde la perspectiva de una economía emergente como la chilena.

\subsection{Línea de Crédito Contingente del FMI}

La línea de crédito contingente (CCL) del FMI ha sido una de las iniciativas para ayudar a prevenir las crisis financieras de mayor interés para economías emergentes como la chilena. Esta línea, que en su oportunidad fue aprobada con muchas expectativas, fue diseñada con el objeto de contribuir a proteger a las economías emergentes con fundamentos económicos relativamente sólidos de eventuales contagios de crisis financieras surgidas en otras economías emergentes, así como reforzar los incentivos a aplicar buenas políticas.

De acuerdo al diseño de la CCL, los recursos que el FMI pone a disposición a través de esta línea se pueden utilizar cuando, como consecuencia de condiciones exógenas al país miembro -como ser, condiciones de contagio de crisis por pérdida de confianza de los agentes económicos- la economía enfrente dificultades de pagos externos. Esta línea se contrata con anticipación a una crisis. Para estos efectos, el país contratante debe cumplir condiciones relativamente estrictas, como contar con políticas sanas de acuerdo con las evaluaciones de Artículo IV que regularmente efectúa el FMI, estar implementando o en proceso de implementar estándares internacionales claves, mantener una relación constructiva con sus acreedores privados y hacer progresos importantes para limitar la vulnerabilidad externa.

En su versión actualmente vigente, el monto total de la línea puede alcanzar a entre tres y cinco veces la cuota del país en el FMI (en el caso de Chile, del orden de entre tres y seis mil millones de dólares aproximadamente), exige el pago de una comisión (commitment fee) de 25 puntos base y la tasa de interés cobrada por los giros parte en 150 puntos base por sobre la tasa base del FMI, llegando a 350 puntos base por sobre esa tasa en la medida que el país se tome más tiempo para pagarla. En caso de necesitar recursos, un cinco por ciento de la línea es de libre disponibilidad, mientras que cerca de un tercio de la línea estaría disponible con relativa rapidez, pero requiere de aprobación del directorio del FMI. Adicionalmente, 
una vez que se apruebe la línea, la permanencia de la misma estará sujeta a la aprobación de los programas de monitoreo que efectuará el FMI periódicamente.

Contrastando con la visión que el acceso a esta línea podría constituirse en un codiciado premio a la aplicación de buenas políticas, esta facilidad no ha tenido aceptación entre los potenciales beneficiarios y hasta ahora ningún país ha contratado la línea. Esto se debe tanto a razones financieras como a una preocupación por las señales adversas que podrían emanar de la contratación de una línea o de su terminación.

En cuanto a los factores financieros, la principal consideración es que la línea de crédito contingente ofrecida por el FMI podría ser insuficientemente líquida, en el sentido que los montos de libre o rápida disponibilidad son bajos. En un contexto en que los países tienen como alternativas de liquidez inmediata sus reservas internacionales, y de liquidez adicional la solicitud de un programa tradicional con el FMI, los incentivos para contratar una CCL aparecen como limitados. Adicionalmente, los costos de contratación y uso de la línea, aunque probablemente atractivos para aquellos países con clasificación de riesgo más desfavorable, no lo son tanto para aquellos países que cumplen más fácilmente con las condiciones de eligibilidad exigidas por la CCL.

Las preocupaciones respecto a las señales que pudiesen entregar la contratación y terminación de una línea han tenido fuerte peso en desincentivar el interés en la CCL. En cuanto a la contratación, no ha existido seguridad que la solicitud de la CCL no sea interpretada por los mercados como un fenómeno de selección adversa, proyectando así una imagen de debilidad en vez de fortaleza en las políticas económicas; dicho de otro modo, la preocupación es que la CCL, en vez de ser una bendición, constituya un estigma para el país contratante. En cuanto a las consecuencias de una eventual terminación de una CCL contratada, ya sea por decisión del país o porque el FMI determinara que éste ya no cumple con los requisitos de elegibilidad, se ha argumentado que el cierre de la línea puede gatillar consecuencias adversas.

Está contemplado que la CCL, como facilidad ofrecida por el FMI, expira en noviembre de 2003. Actualmente, el FMI se encuentra revisando las características de la línea, con el objeto de examinar las preocupaciones antes mencionadas. En la práctica, sin embargo, es improbable que su vigencia sea extendida.

Una CCL efectiva hubiese podido constituir en un instrumento proactivo para reforzar los esfuerzos de prevención de crisis, pero lamentablemente no ha podido diseñarse una que funcione en la práctica. Desde esta perspectiva, probablemente será más provechoso que el FMI busque maneras de diseñar o rediseñar otros instrumentos de préstamos que no requieran identificar de antemano qué países son o no elegibles, pero que sean más efectivos que los actuales en prevenir crisis, así como en responder rápidamente y con suficientes recursos a las necesidades de liquidez de aquellos países que aplican políticas sólidas. 


\subsection{Mecanismos de reestructuración de deuda soberana}

Como resultado de fuertes críticas a los programas de apoyo financiero oficial liderados por el FMI desde mediados de los noventa, amplificadas tras la crisis en Argentina, en los últimos años han tomado un rol protagónico en los foros financieros internacionales las propuestas de revisión de los mecanismos de reestructuración de deuda externa soberana.

Estas propuestas encuentran su fundamento económico en la preocupación de que, en aquellos casos de países que han acumulado niveles de deuda insostenibles, sus gobiernos postergan demasiado atacar y resolver el problema, agravando los costos para sus economías, sus acreedores y la comunidad internacional. Entre las razones que han contribuido a ese comportamiento se ha identificado la falta de mecanismos que permitan reestructurar deudas de manera predecible y ordenada, lo cual dificulta y hace significativamente más costoso iniciar un proceso de reestructuración temprana. Subyacen a este diagnóstico la existencia de varias imperfecciones en los mercados, incluyendo las asimetrías de información entre deudores y acreedores, la dificultad de los deudores para comprometerse con un programa económico creíble, el riesgo moral que puede llevar a los deudores y acreedores a tomar riesgos excesivos, un problema de soberanía y, especialmente, un importante problema de coordinación o acción colectiva de los acreedores. Este último se ha acentuado desde la década pasada, en la medida que los países deudores crecientemente han reemplazado su financiamiento externo a través de créditos otorgados por unos pocos bancos acreedores por la emisión de bonos comprados en última instancia por cientos o miles de agentes económicos en distintos países y jurisdicciones legales.

El debate sobre mecanismos de reestructuración de deuda también ha sido impulsado en parte por algunos que, preocupados del riesgo moral que podrían causar en general los préstamos oficiales liderados por el FMI, ven en el desarrollo de esos mecanismos principalmente una manera de reducir la frecuencia y el monto de recursos que prestan los organismos multilaterales. Esta motivación, sin embargo, no se compadece con la evidencia que la enorme mayoría de los préstamos oficiales son para enfrentar problemas de liquidez y no de solvencia, que es el tipo de problemas que los mecanismos de reestructuración de deuda intentan abordar. Asimismo, no considera los efectos de la creciente integración de los mercados financieros internacionales y la volatilidad de los flujos de capitales en el monto de recursos necesarios para prevenir y resolver problemas de liquidez.

Las dos propuestas principales que se han planteado para mejorar la reestructuración de deuda (SDRM y CACs) ya fueron introducidas brevemente en la sección anterior. En esencia, la propuesta SDRM plantea modificar los estatutos del FMI para establecer un marco legal universal que facilite las reestructuraciones de deuda soberana, en la línea de las leyes de bancarrota que se aplica a las empresas en los EE.UU. y la mayoría de los países. La propuesta de CACs, en tanto, plantea ampliar el uso y contenido de las cláusulas de acción colectiva que se utilizan habitualmente en los contratos de los bonos emitidos en algunas jurisdicciones, notablemente en Gran Bretaña. 
El contenido específico del SDRM propuesto por el FMI ha evolucionado desde que la idea fuera presentada por primera vez por Anne Krueger, Subdirectora Gerente de la institución, en noviembre de 2001 (Krueger, 2002). Los elementos más esenciales y perdurables de esa propuesta fueron presentados formalmente en abril del 2003, a petición del Comité Monetario y Financiero Internacional del FMI. Estos incluyen los siguientes: (1) que una supermayoría de acreedores (por ejemplo, $75 \%$ ) agregadas a través de distintas emisiones puedan votar para aceptar nuevas condiciones de pago, bajo un acuerdo de reestructuración que sería forzoso para todos los acreedores afectados; (2) se incluirían provisiones que impedirían la iniciación de acciones individuales de acreedores que puedan complicar el proceso de negociación, o retrasar el acuerdo de una reestructuración que sea aceptable para una amplia mayoría de acreedores; y, (3) se crearía un foro independiente de resolución de disputas que se establecería para verificar los derechos de los distintos acreedores, asegurar la integridad del proceso de votación y adjudicar disputas que puedan surgir después de la activación del mecanismo.

En cuanto a las CACs, impulsada entre otros desde abril de 2002 por John Taylor, Subsecretario del Tesoro de EE.UU., las diversas propuestas que se han planteado tienen en común la inclusión de cláusulas de reestructuración y acción mayoritaria en las emisiones de bonos, las cuales especifican condiciones similares a las de los elementos (1) y (2) mencionados en el párrafo anterior, pero a nivel de cada emisión particular (Taylor, 2002). Las diferencias entre las propuestas se manifiestan en aspectos específicos pero importantes de esas cláusulas, tales como los porcentajes requeridos para aprobar las reestructuraciones e iniciaciones de acciones. Asimismo, hay diferencias sustantivas en cuanto a la inclusión de otras cláusulas adicionales. En el caso de las propuestas más completas y ambiciosas, cabe destacar las cláusulas de representación, que permiten a un agente o grupo de agentes a negociar en representación del conjunto de acreedores. En el Cuadro 4 se presentan las cláusulas de acción colectiva contenidas en algunas de las principales propuestas que se han efectuado hasta el presente.

No obstante el origen común de ambos enfoques, en cuanto a que ambos apuntan a resolver el problema de acción colectiva de múltiples acreedores en su relación con un deudor, ha habido extenso, y a veces apasionado, debate sobre sus relativos méritos y desventajas. El SDRM ha sido cuestionado como un mecanismo muy rígido y centralizado, que no toma en cuenta realidades diferentes que pueden enfrentar distintos deudores y acreedores y que pueden coartar las iniciativas privadas para solucionar el problema. Por su parte, la fórmula de CACs ha sido criticada porque no resuelve el problema de agregación de los intereses de acreedores a través de distintas emisiones de deuda y jurisdicciones, aspectos que el SDRM sí lograría a través de su validez universal y la creación del foro de resolución de disputas. También se han planteado críticas cruzadas entre los proponentes de ambos enfoques respecto de la rapidez con que podrían aplicarse de manera generalizada.

Por el insuficiente apoyo que ha generado, la propuesta de SDRM fue virtualmente descartada en la reunión del IMFC de abril de 2003 y parece difícil que 


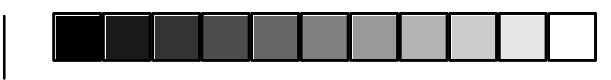

$\phi$

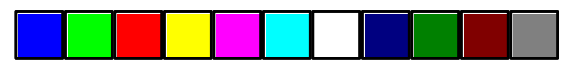

CRISIS FINANCIERAS INTERNACIONALES

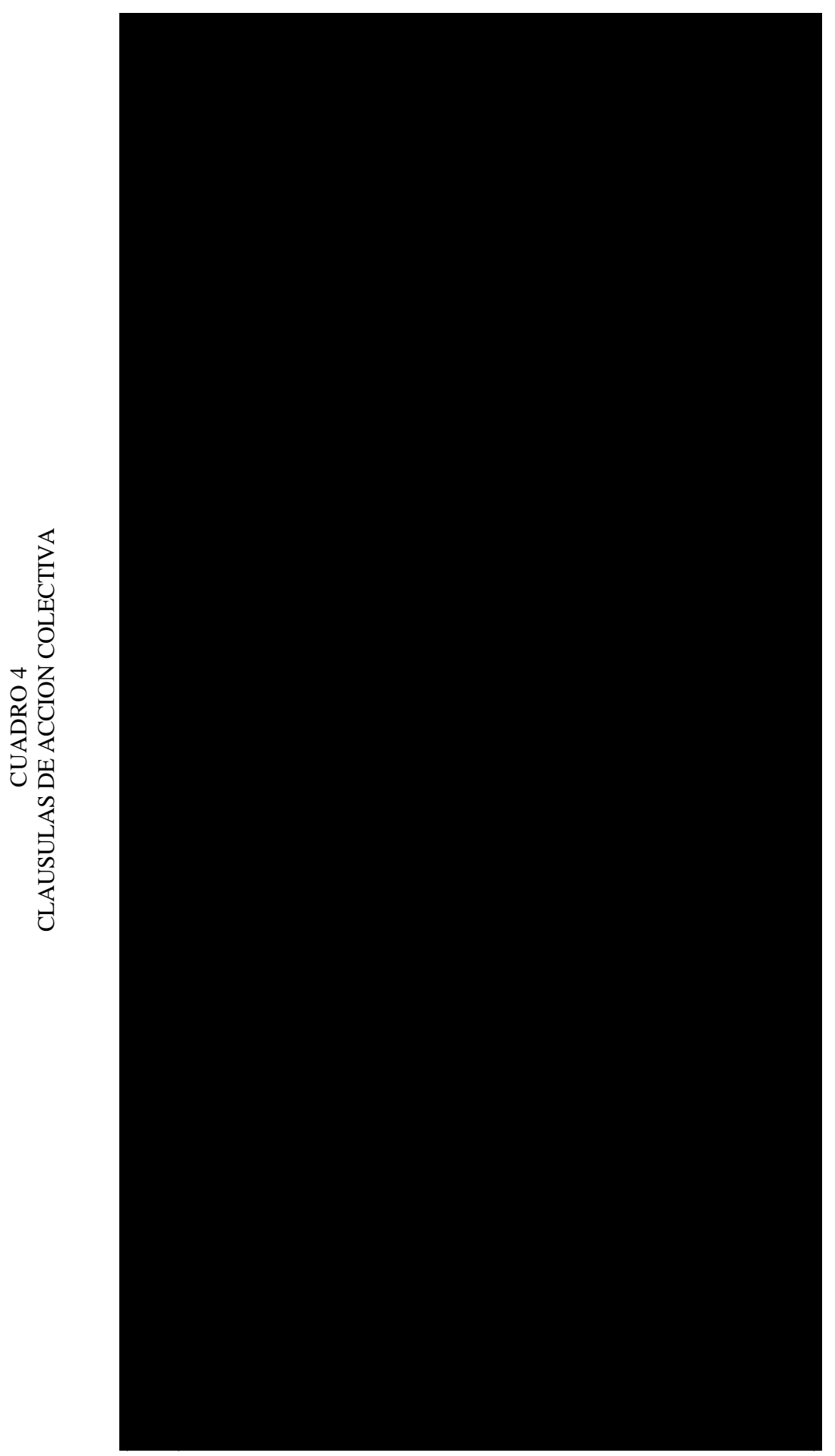

$\phi$ 
en los próximos años se genere un consenso suficiente como para avanzar en esa dirección. En contraste, no se observa una oposición activa a las CACs, las cuales además recientemente han ido ganando terreno a través de la emisión de bonos con dichas cláusulas por parte de México, Brasil y Uruguay. De este modo, todo indica que la pregunta relevante de política que deberán hacer próximamente otras economías emergentes sería si incluir también esas cláusulas en sus nuevas emisiones de bonos.

Para tomar esa decisión, un aspecto central que esas economías deberán evaluar será el efecto que dichas cláusulas tengan sobre el costo de su financiamiento externo. En principio, el signo de este efecto es indeterminado. Por una parte, las CACs pueden ser valoradas favorablemente por los acreedores por hacer más eficiente un eventual proceso de reestructuración de deuda y contribuir de ese modo a disminuir los costos de ese proceso en caso que haya una reestructuración. Por otra parte las CACs también pueden aumentar la probabilidad que eventualmente ocurra una reestructuración como resultado de un mayor riesgo moral. Así, la evidencia empírica sobre el costo de las CACs tiene gran importancia.

La evidencia disponible sobre bonos emitidos en Gran Bretaña y otras jurisdicciones, examinadas por Eichengreen y Mody (2000) y Becker, Richards y Thaicharoen (2001), no sugiere que las CACs tengan consecuencias adversas relevantes sobre el costo de financiamiento en el caso de deudores de menor riesgo. De hecho, Eichengreen y Mody (2000) incluso encontraron que los deudores de menor riesgo se beneficiarían a consecuencia de ese tipo de cláusulas. En el caso de deudores de riesgo crediticio más alto la evidencia es más mezclada, ya que mientras los primeros antes mencionados encontraron efectos adversos, los últimos cuestionaron dichos resultados, encontrando por su parte resultados estadísticamente no significativos.

La reciente emisión de bonos con CACs por parte de México a fines de febrero de 2003 parece confirmar la evidencia antes mencionada. Como se muestra en el Cuadro 5, el spread de esta emisión es comparable a losspreads de bonos sin CACs y duración comparable. Lo mismo sugiere la alta demanda por bonos con CACs colocados por Brasil un par de meses más tarde, la cual superó en siete veces el tamaño de la emisión.

CUADRO 5

RENDIMIENTO BONOS GLOBALES DE LOS ESTADOS UNIDOS MEXICANOS

\begin{tabular}{lccc}
\hline Bono & $\begin{array}{c}\text { Años Para } \\
\text { Vencimiento }\end{array}$ & $\begin{array}{c}\text { Rendimiento al } \\
\text { Vencimiento }\end{array}$ & $\begin{array}{c}\text { Margen Sobre Bonos del } \\
\text { Tesoro Norteamericano a } \\
10 \text { años }\end{array}$ \\
\hline UMS 2013 & 9.0 & $6.575 \%$ & $2.78 \%$ \\
Nuevo UMS 2015 * & 12.0 & $6.918 \%$ & $3.12 \%$ \\
UMS 2016 & 13.6 & $7.277 \%$ & $3.48 \%$ \\
UMS 2019 & 16.8 & $7.582 \%$ & $3.71 \%$ \\
\hline
\end{tabular}

(*) Incluye cláusulas de acción colectiva (CACs)

Fuente: Secretaría de Hacienda y Crédito Público. 
Aunque todavía es temprano para establecer un veredicto definitivo sobre la materia, de mantenerse la evaluación de que la inclusión de CACs no eleva los costos de financiamiento, los países emergentes que no las han incluido probablemente comenzarán a utilizarlas. En efecto, si bien puedan existir dudas significativas sobre su utilidad en la práctica, debido a la ya mencionada falta de universalidad en la cobertura e interpretación de las cláusulas que contendrían los contratos, es improbable que la introducción de esas cláusulas signifique un retroceso respecto a la situación actual en materia de reestructuración de deudas, especialmente si son aceptadas voluntariamente por los acreedores. ${ }^{8}$

Más allá de la conveniencia de incluir o no CACs en las futuras emisiones de deuda, ¿cómo debe evaluarse el que la comunidad financiera internacional deseche, al menos por ahora, la alternativa de un SDRM? Al respecto, no puede dejar de notarse que las aparentes insuficiencias de la situación actual y de las CACs ya mencionadas sugieren que sí sería preferible que eventualmente existiese algún mecanismo general que permita que esas reestructuraciones sean más eficientes. Dado el consenso en que los países deben tener leyes e instituciones que establezcan procedimientos claros y ordenados para enfrentar y resolver situaciones de bancarrota, no es fácil visualizar por qué no debiesen existir procedimientos comparables a nivel internacional. La nota de cautela es que, incluso en el caso de los países individuales, esos mecanismos legales e institucionales no siempre son los más adecuados, por lo que no cualquier SDRM tendría que merecer apoyo.

Sin perjuicio de lo anterior, desde la perspectiva de una economía emergente como la chilena, dar vuelta la página en cuanto a la propuesta SDRM probablemente sea beneficioso respecto de la situación actual. En efecto, ya que el tema de reestructuración de deuda soberana apunta a resolver problemas de insolvencia, los cuales en el caso de los países son mucho menos frecuentes que los problemas de liquidez, se trata de un tema de importancia bastante más limitada que lo que sugieren el tiempo y debate dedicados por la comunidad financiera internacional. Desde esta perspectiva, y en un contexto en que el número de temas y debates que esa comunidad puede atender son limitados, se abre una oportunidad para que ésta vuelva a prestar atención prioritaria a la prevención de crisis, incluyendo la promoción de buenas políticas económicas y la adecuada provisión de liquidez.

\section{Comentarios Finales}

El SFI -compuesto por deudores soberanos, una multiplicidad de acreedores privados y el FMI- sufre de un gran número de imperfecciones. Estas se reflejan en contratos incompletos, fuertes ciclos de sobreendeudamiento de eco-

Aun en el caso que la inclusión de CACs elevara el costo de financiamiento, no necesariamente se desprende que un país debiera abstenerse de incorporarlas en sus emisiones de bonos. Ver Kletzer (2002). 
nomías en desarrollo seguidos por salidas masivas de capitales, frecuentes episodios de crisis de cuenta de capitales, problemas severos de iliquidez e insolvencia, contagio internacional y altos costos derivados de períodos prolongados de repudio o moratoria de deuda soberana y falta de acceso a capitales privados nuevos.

Las imperfecciones del SFI son similares a las que se observan en los sistemas financieros nacionales en cuatro categorías: el descalce entre madurez de proyectos y financiamiento, las políticas inadecuadas por parte del deudor, el comportamiento de manada e imperfecciones de información y el exceso de exposición al riesgo por la existencia de un PUI. Estas imperfecciones causan o refuerzan las posibilidades de crisis de liquidez o de solvencia. A las imperfecciones anteriores se agregan dos conjuntos de imperfecciones propias del SFI, que se derivan de la existencia de estados soberanos y de la propia existencia del PUI internacional. Estas últimas elevan aún más la probabilidad de ocurrencia de crisis de liquidez o de solvencia, en países individuales o en regiones enteras.

El PUI internacional en su forma actual (el FMI) presenta diferencias importantes con un PUI nacional (un banco central o gobierno). Por una parte, es más débil en su capacidad de asistencia financiera, por carecer de recursos comparables a los de un PUI nacional. Por otra parte, el FMI juega un rol central al proveer un sello de aprobación a los programas de ajuste aplicados por países en crisis, sin el cual no son capaces de obtener financiamiento de otras IFIs y de los mercados privados de capitales. No obstante, el rol tradicional que ha jugado el FMI también ha contribuido a las imperfecciones observadas en el SFI.

En la última década han florecido las propuestas de reforma del SFI - la así llamada "nueva arquitectura financiera internacional" - que apuntan a superar las imperfecciones del SFI en tres dimensiones: una mejor prevención de crisis financieras, una mejor resolución de crisis financieras y una mejor gobernabilidad del PUI internacional representado por el FMI.

Muchas propuestas realizadas son académicas. No obstante, ellas han servido para que el FMI (y, en menor grado, otras IFIs) estén apoyando o implementando activamente reformas que incluyen la adopción global de estándares y códigos internacionales en 12 áreas claves para la estabilidad macroeconómica y financiera nacional e internacional, el monitoreo y la condicionalidad de la asistencia financiera por las IFIs y las reformas que refuerzan la gobernabilidad del FMI en su rol de PUI internacional.

Las reformas referidas a mejorar la prevención de crisis son particularmente relevantes para las economías emergentes más avanzadas. En esta área, la línea de crédito contingente del FMI, creada para ayudar a esas economías a prevenir los riesgos de contagio provenientes de problemas en los mercados financieros globales, no ha cumplido su propósito. Debido al temor a las señales adversas que su contratación y terminación podría generar, así como porque dicho instrumento no parece otorgar un nivel de liquidez significativamente mayor al que puede proveer otras formas de financiamiento oficial, este instrumento probablemente será discontinuado. Mirando a futuro, un desafío importante para la comunidad financiera internacional será desarrollar otros instrumentos financieros que permitan a las economías emergentes con políticas económicas sólidas disponer de 
suficiente liquidez en momentos de fuerte turbulencia en los mercados financieros internacionales.

En años recientes, la mayor parte del debate reciente sobre reformas al SFI se ha centrado más bien en la resolución de crisis. Aunque la relevancia y costo de oportunidad de ese debate desde la perspectiva de las economías emergentes más avanzadas es cuestionable, el propósito de desarrollar mejores mecanismos de reestructuración de deuda es positivo. En el caso de aquellos países que eventualmente acumulen deudas insostenibles, ello reduciría los costos económicos que pagan esos países, sus acreedores y la comunidad internacional debido a la falta de mecanismos eficientes de reestructuración de deudas.

En la actualidad no existe ánimo como para cambiar los estatutos del FMI de modo de implementar un sistema de bancarrota internacional como el propuesto por el SDRM, pero se observa un creciente impulso al uso de CACs en las emisiones de bonos soberanos. En este contexto, la principal decisión de política que asoma en esta materia para las economías emergentes es si conviene incluir ese tipo de cláusulas en futuras emisiones y, en tal caso, cuáles. En la medida que se mantenga la percepción que esas cláusulas no tienen costos relevantes, no habría por qué oponerse. Sin embargo, debe tenerse presente que no es evidente que un uso incluso generalizado de CACs mejore sustancialmente los procesos de reestructuración de deuda. En particular, las CACs consideradas en la actualidad no resuelven el problema de agregación a través de distintas emisiones de deuda y jurisdicciones. De este modo, propuestas al estilo del SDRM eventualmente podrían recobrar notoriedad.

Desde el punto de vista de un país como Chile es positivo no centrar la discusión exclusivamente en resolución de crisis. Esto, porque tener buenos mecanismos de resolución puede limitar la profundidad de las crisis, pero no asegura que sean menos probables. Desde el punto de vista de países que están lejos de una crisis, pero pueden sufrir contagio, es importante prevenir problemas de otros.

Las últimas crisis han entregado importantes lecciones respecto de qué políticas son más o menos adecuadas. De hecho, con facilidades de liquidez bien diseñadas y la implementación de buenas políticas, una proporción elevada de las crisis es evitable. Es necesario darle una oportunidad a lo aprendido. No obstante, continúa siendo cierto que existen enormes dificultades para separar iliquidez de solvencia. Asimismo, es difícil pensar en que un PUI internacional llegue a tener grandes recursos.

Los países, por lo tanto, deben tomar decisiones en un ambiente de elevado riesgo. Al respecto, éstos deben tener presente que no existe ningún sustituto a los buenos fundamentales, reflejados en la adopción y el perfeccionamiento de políticas macroeconómicas prudentes y sostenibles y de un marco de políticas e instituciones consistentes con una economía de mercado abierta, transparente e integrada al mundo. 
Becker, T., A. Richards and Y. Thaichareon (2001), "Bond Restructuring and Moral Hazard: Are Collective Action Clauses Costly?" Fondo Monetario Internacional, Working Paper No. WP/01/92.

Caballero, R. (2002),"Enfrentando la Vulnerabilidad Externa de Chile: Un Problema Financiero". Economía Chilena 5(1): 11-36.

Caballero, R. (2003), "The Future of the IMF”. Manuscrito, Massachusetts Institute of Technology, Julio.

Calomiris, C. (1998), "Blueprints for a New Global Financial Architecture". Manuscrito, Columbia Business School.

Calvo, G. (2002), "Globalization Hazard and Delayed Reform in Emerging Markets". Economía 2(2): 1-29.

Calvo, G., y C. Reinhart (1999), "When Capital Inflows Come to a Sudden Stop: Consequences and Policy Options". Manuscrito, University of Maryland, Junio.

De Gregorio, J., B. Eichengreen, T. Ito, C. Wyplosz (1999), AnIndependentandAccountable $I M F$. Geneva Reports on the World Economny 1. Centre for Economic Policy Research. International Center for Monetary and Banking Studies.

Edwards, S. (1998), "Capital Flows, Real Exchange Rates, and Capital Controls: Some Latin American Experiences" National Bureau of Economic Research Working Paper 6800, Noviembre.

Eichengreen, B. (1999), Toward a New International Financial Architecture: A Practical Post-Asia Agenda. Washington: The Institute for International Economics.

Eichengreen, B. y A. Mody. (2000), "Would Collective Action Clauses Raise Borrowing Costs?" National Bureau of Economic Research, Working Paper No. 7458.

Eichengreen, B. y A. Mody (2003), "Is aggregation a problem for sovereign debt restructuring?". CEPT Discussion Paper 3771.

Fischer, S. (1999), "On the Need for an International Lender of Last Resort". Journal of Economic Perspectives 13(4): 85-104.

Fondo Monetario Internacional (2001), "The IMF's Contingent Credit Lines. A Factsheet". IMF External Relations Department. Junio.

Fondo Monetario Internacional (2003), "Proposals for a Sovereign Debt Restructuring Mechanism(SDRM). A Factsheet". IMF External Relations Department. Enero.

Garten, J. (1998), "In this Economic Chaos, a Global Central Bank Can Help". International Herald Tribune, Septiembre.

International Monetary Fund (2003), "Report of the Managing Director to the International Monetary and Financial Committee on the IMF's Policy Agenda", IMF website, abril.

Kaminsky, G. y C. Reinhart (1999), "The Twin Crises: The Causes of Banking and Balance-of-Payments Problems". American Economic Review 89(3): 473-500.

Kaufman, H. (1998), "Preventing the Next Global Financial Crisis". Washington Post, enero.

Kenen, P. (2002), “The International Financial Architecture. Old Issues and New Initiatives". Manuscrito, Princeton University, Febrero. 
Kletzer, K. M. (2002), "Sovereign Bond Restructuring: Collective Action Clauses and Official Crisis Intervention", University of California, Santa Cruz, Working Paper $\mathrm{N}^{\circ} 533$.

Krueger, A. (2002), A New Approach to Sovereign Debt Restructuring. Washington, DC: Fondo Monetario Internacional (Abril).

Krueger, A. (2002), "Sovereign Debt Restructuring Mechanism: One Year Later”. Presentado en la Conferencia "Macroeconomic Stability, Financial Markets and Economic Development" en el Banco de México. IMF External Relations Department. Noviembre.

Lerrick, A. y A. Meltzer (2001a), "Beyond IMF Bailouts: Default without Disruption”. Quarterly International Economics Report, Mayo.

Lerrick, A. y A. Meltzer (2001b), "Blueprint for an International Lender of Last Resort". Manuscrito. Carnegie Mellon University. Octubre.

Meltzer, A. (1998), “Asian Problems and the IMF”. Testimonio preparado para el Joint Economic Committee del Congreso de EE.UU. Febrero.

Meltzer, A. (2000), "Statement of Allan Meltzer on the Report of the International Financial Institution Advisory Commission". Senado del Congreso de EE.UU., Marzo 9.

Ortiz, G. (2002), “Crisis Recientes en Mercados Emergentes: ¿Qué es lo que hemos aprendido?" Boletín de CEMLA XLVIII(4): 155-87.

Raffer, K. (1990), “Applying Chapter 9 Insolvency to International Debts: An Economically Efficient Solution with a Human Face". World Development, 18(2): 301313.

Rogoff, K. (1999), "International Institutions for Reducing Global Financial Instability." NBER WP 7265.

Sachs, J. (1995), "Do We Need an International Lender of Last Resort?". Princeton University, Conferencia Frank Graham Memorial.

Soros, G. (1997), “Avoiding a Breakdown: Asia's Crisis Demands a Rethink of International Regulation". Financial Times, diciembre.

Soros, G. (1998), "The Crisis of Global Capitalism". New York: Public Affairs Press.

Taylor, J. (2002), "Sovereign Debt Restructuring: A U.S. Perspective.” Treasury News, www.treas.gov/press/releases/po2056.htm. 